INVESTIGACIÓN/RESEARCH

Recibido: 18/02/2015---Aceptado: 20/04/2015---Publicado: 15/06/2015

\title{
¿SE MERECE LA PUBLICIDAD UN MUSEO? ESTUDIO Y ANÁLISIS MUNDIAL DE LOS MUSEOS DE PUBLICIDAD
}

Consuelo Balado Albiol 1: Universitat Jaume I de Castellón. España.

balado@uji.es

Eva Breva Franch: Universitat Jaume I de Castellón. España

franch@uji.es

\section{RESUMEN}

Los cambios acaecidos tanto en la concepción de los museos a partir de los años 70, como en la comunicación publicitaria en las últimas décadas, hacen reflexionar a las autoras sobre la inexistencia de un museo internacional de publicidad que disponga de un espacio físico para mostrar sus colecciones y que se complete con una zona de estudio o investigación en la materia. Así, partiendo del análisis de la trascendencia que ha tenido la publicidad para la economía de mercado y la sociedad por una parte y de cómo las nuevas tecnologías de la información y comunicación han incidido en la forma de concebir la comunicación por otra, se establecen las líneas museológicas en las que debería centrarse este hipotético museo a partir del estudio de la bibliografía sobre el tema. En una segunda fase se ha procedido al análisis pormenorizado de los proyectos museísticos, con sede física, que abordan la materia publicitaria en la actualidad. Del resultado de dicho análisis, y sin olvidar el marco teórico, se concluye que debido a la amplitud de la materia, un museo sobre esta disciplina se debe plantear como un ente nacional pero con perspectivas y relaciones internacionales a través de la investigación y el estudio. Hecho que se puede llevar a cabo gracias a la tecnología que nos acerca a casi cualquier experiencia.

\section{PALABRAS CLAVE}

Publicidad-Museo-Comunicación-Sociedad-Educación-Experiencias-InvestigaciónEconomía-Internacional

\footnotetext{
${ }^{1}$ Consuelo Balado Albiol: Llicenciada en Ciencias de la Información por CEU San Pablo, Valencia y doctora en Ciencias de la Comunicación por la Universitat Jaume I de Castellón.

balado@uji.es
} 


\title{
DOES ADVERTISING DESERVE A MUSEUM? STUDY AND GLOBAL ANALYSIS OF THE ADVERTISING MUSEUMS
}

\begin{abstract}
The changes occurring in both the design of museums from the 70s, and advertising communications in recent decades, has provoked the reflexion about the absence of an international museum of advertising that has a physical space to showcase their collections and an area of study or research in this field. Thus, from the analysis of the importance that has taken advertising for market economy and society on the one hand and how the new technologies of information and communication have influenced the way of thinking about communication on the other, the authors establish the museological lines where this hypothetical museum should focus from the study of the bibliography about the subject. In a second phase they proceeded with a detailed analysis of museum projects, physically based, addressing the advertising field today. The outcome of the analysis, without forgetting the theoretical framework, it is concluded because of the breadth of the subject, a museum about the discipline should be considered as a national entity but with prospects and international relations through research and study. This fact can be carried out thanks to the technology that brings us to almost any experience.
\end{abstract}

\section{KEY WORDS}

Advertising-Museum-Communication-Society-Education-Experience-ResearchEconomy-International.

\section{INTRODUCCIÓN}

La historia de la publicidad arranca con los inicios del comercio, por tanto resulta extraño que la gran actividad generada por esta técnica, tanto en lo referente a materiales creados como a inversión generada, y que además es considerada por algunos como un arte, no haya merecido hasta el momento la atención suficiente para que la misma se vea reflejada en un museo dedicado en exclusiva y de forma internacional a esta materia.

Quizá la misma incapacidad de abarcar en un único espacio tanta información y tanto material creado a lo largo de siglos en todo el mundo haya hecho imposible realizar un proyecto como este. Ya que, en la actualidad, solo existen seis experiencias que de alguna manera abordan en un espacio físico la exhibición parcial de una muestra de la publicidad de los países en los que se encuentran ubicados dichos museos.

Si bien es cierto que virtualmente existen un gran número de páginas web que en diferentes países ostentan el título de "museos de publicidad", no lo es menos que, al igual que los museos "físicos", solo abordan parcialmente una materia tan extensa como es la comunicación publicitaria. 


\subsection{Evolución en el concepto de museo a partir de los años 70}

En la década de los 70 los museos empezaron a variar su concepción, dejando de considerar al público únicamente como un elemento pasivo que contempla, para tratarlo como un sujeto activo, que interactúa con él. El propósito era crear lugares de relación, a través de cursos, talleres, conferencias, congresos, guías didácticas, exposiciones... en las que el espectador dispusiese de una serie de elementos que le permitieran interactuar con todo ese universo que rodea al mero espacio físico.

El importante incremento en la cantidad de museos que se abrieron a partir de los años 80, ha hecho que los museos dejen de ser instituciones dedicadas exclusivamente a exhibir obras de arte para transformarse en centros culturales que desarrollan multitud de actividades para un público más diverso (Vidarte, 2004). Esta apertura a la sociedad es lo que les ha convertido en lugares de ocio, en espacios cercanos donde poder disfrutar, no solo de la experiencia museística, sino de participar en las actividades complementarias que ofrecen la mayoría de estas instituciones.

García Serrano considera que el cambio de mentalidad y de concepto que se está operando socialmente en relación con los museos tiene que ver con la renovación que han sufrido los conceptos de cultura y de institución cultural.

La cultura ha dejado de ser privilegio de unos pocos, se ha diversificado y desacralizado, considerándose como un bien social común de libre derecho y una conquista de la civilización del ocio. Además la denominada cultura de masas ha multiplicado los horizontes de los productos de la actividad cultural, generando, además de una revolución conceptual, una extraordinaria diversificación y multiplicación de los bienes culturales museificables. En otras palabras, si la nueva civilización ha creado una amplia y generalizada conciencia social de la necesidad de conservar y revitalizar los testimonios culturales, y se ha multiplicado la producción cultural y, por tanto, el número de objetos «a conservar», la consecuencia clara es que cada día harán falta más museos, dotados de más medios y con un planteamiento mucho más tecnificado y racionalizado. (García Serrano, 2000, p.16)

En cuanto a las instituciones culturales, afirma que con la implantación a gran escala del marketing y las técnicas asociadas a él, la cooperación internacional en el terreno cultural definiendo frentes, acciones y políticas culturales comunes han evidenciado la necesidad urgente de reciclarse.

Es en este contexto donde aparece la nueva museología, que según el criterio Alonso (2006, p.25) es un movimiento internacional que ha conseguido remover desde sus cimientos el secular "sosiego", tanto de la institución museística como del patrimonio cultural, en busca de un nuevo lenguaje, expresión y mayor apertura, dinamismo y participación sociocultural, la "nueva museología" preconiza e impulsa una tipología distinta de museo.

Con todos estos aires de cambio que vienen de la década de los 70 se llega a la definición que en 1986 ofrece la UNESCO, a través de su organismo de museos, el ICOM, sobre el museo como el establecimiento permanente para conservar, estudiar, poner en valor por medios diversos, y esencialmente exponer para delectación y educación del público, las colecciones de interés artístico, histórico, científico o 
técnico. El museo es un medio de comunicación, el único dependiente de lenguaje no verbal, de objetos y de fenómenos demostrables. El museo es una institución al servicio de la sociedad que adquiere, comunica y, sobre todo, expone con la finalidad del estudio, del ahorro, de la educación y de la cultura, testimonios representativos de la evolución de la naturaleza y del hombre.

Otro punto de vista que incide en los notables cambios que se han producido en la museología contemporánea es el de León (1990, p.58), que dentro de su clasificación de museos de Tecnología, incluye un Museo de la Técnica Publicitaria (1990, p.149), el cuál considera que sería de gran importancia porque manifestaría una faceta típica de la civilización contemporánea:

Por una parte, pondría al hombre frente a un objeto que sólo conoce desde una dimensión utilitaria y al que podría acceder aunando conocimiento y experiencia, relacionando contenidos mentales $y$ funciones reales $y$, consecuentemente, por otra parte, tomaría una nueva actitud ante sí mismo y ante el objeto, actitud concretizada en una disminución de confort práctico que le haría rechazar otro más nefasto: el confort intelectual y la mecanización de sus actitudes. (León, 1990, p.149).

Se puede concluir pues que el museo actual busca cada vez más convertirse en un lugar donde suceden cosas y no mantenerse exclusivamente en su función primigenia como conservador y contenedor de cosas más o menos atractivas, más o menos curiosas. Para Riaño (2004), el museo deja de ser un espacio donde estar para convertirse en un territorio intelectual donde transitar. El museo deja de ser solo un contenedor de objetos, para convertirse en un espacio que asiste al que lo visita para poder establecer relaciones con diferentes procesos y contextos culturales y científicos dentro de parámetros más dinámicos participativos y de seducción.

Así, la visita al museo ya no supone -al menos, en el grado superlativo de antes- un frío monólogo de obras alejadas del público en tiempo y espacio sino una aproximación gradual a un diálogo abierto entre la obra y el espectador, mediatizados ambos por el papel intermediario del museo y sus dirigentes.

\subsection{El interés social de la publicidad}

Resulta imposible desligar lo que ha sido la historia de la publicidad de lo que es la historia del ser humano y su progreso, ya que por naturaleza el contexto en el que se genera la publicidad es la sociedad de mercado. La publicidad por tanto está unida a la historia a través de la evolución económica, comercial, técnica y financiera e, inevitablemente, al desarrollo de la sociedad y su cultura. Eguizábal (1998, p.12) no entiende la historia de la publicidad si no va de la mano de todas aquellas manifestaciones que han influido en su evolución: tecnología, cambios sociales y políticos, guerras, industria, comercio, arte, hallazgos científicos y técnicos... Pero ve las primeras manifestaciones publicitarias como algo puramente primitivo e innato ya que, según él, la publicidad moderna, tal y como hoy la entendemos, nace del capitalismo burgués tras la revolución industrial. Cita en su libro Historia de la Publicidad:

Donde haya una ciudad habrá comercio, y donde haya comercio se hará necesario llamar la atención [...]. Los comerciantes tendrán que hacerse notar, 
cuanto mayor sea el ruido que se levante en esa gran urbe, mayores tendrán que hacerse sus gritos. La existencia de la publicidad, e incluso la de sus manifestaciones más primarias, indica, entonces, un grado de civilización, civilización urbana, cultura del comercio. (Eguizábal, 1998, p.19)

Quizá por su carácter cotidiano, la publicidad es un fenómeno interconectado con campos tan diferentes como la economía, el lenguaje, la sociología, la ética, la psicología o el arte. Desde cada uno de ellos se llevan a cabo estudios y se expone lo que la caracteriza.

La publicidad nace en la economía de mercado, en la que todo acaba reduciéndose a cifras, pero la actividad publicitaria no puede quedar reducida únicamente a eso, porque está unida a la historia, a la evolución económica, social, cultural y tecnológica. Como elemento cotidiano de nuestras vidas, forma parte de nuestro sistema de información y de referencias y además, como vehículo de comunicación, "el sistema publicitario es un elemento dinamizador de la economía que nos afecta a todos en más actividades de nuestra vida de las que pensamos" (Moreno y García Serrano, 2006, p.129).

Alba (1976, p.7) considera, que esta gran implicación de la publicidad con la sociedad es la que le hace estar tan en boca de muchas disciplinas. Es esa abertura, esa exposición a todas las miradas la que explica, y hasta justifica los variados juicios de valor que se hacen sobre ella. Economistas, humanistas, moralistas, pedagogos, lingüistas, políticos, poetas $\mathrm{y}$, naturalmente publicitarios... todos parecen tener opción y derecho para pronunciarse sobre el fenómeno de la publicidad, lo que en el fondo da una idea consistente de su valor y complejidad.

Desde una visión sociológica Baudrillard (2009) considera la publicidad el medio masivo más notable de nuestra época. Y esa función de comunicación masiva no procede de sus contenidos, de sus modos de difusión, de sus objetivos manifiestos (económicos y psicológicos) ni tampoco de su volumen ni de su público real (aun cuando todo esto tiene su importancia y le sirve de apoyo), procede de su lógica misma de medio autónomo, es decir, "de un medio que no remita a objetos reales, a un mundo real, a un referente, sino que remite de un signo al otro, de un objeto al otro, de un consumidor al otro" (Baudrillard, 2009, p.148).

Para un publicitario como Caro (1994, p.132) una campaña que triunfa y que acaba gozando de gran notoriedad pública no pertenece a nadie. Porque pasa a ser un fragmento de la "iconosfera contemporánea", es decir, pasa al imaginario colectivo. Y va un poco más allá cuando argumenta que "la publicidad proclama ante los ojos de la sociedad lo que ésta realmente sueña, piensa o desea, revelando así aspectos de ella misma que tal vez no se atreve a confesarse o que algunos de sus sectores preferirían mantener ocultos" (Caro, 1994, p.161). Cree tan firmemente en el importante valor de reflejo de la sociedad que supone la publicidad, que incluso le otorga el papel de juez para evaluar lo que se puede mostrar y lo que es tabú, un espacio sacralizado donde se señaliza lo que resulta socialmente admisible.

Aunque el creativo publicitario Toni Segarra (2009, p.182) es plenamente consciente del carácter perecedero de la publicidad y por extensión de su futilidad, no deja de apreciar la importancia de esta técnica como reflejo de la sociedad en la que se produce. Pese a que afirme que la publicidad es un reflejo "idealizado, bobalicón, 
intrascendente" (Segarra, 2009, p.183) del tiempo que vivimos y de quienes lo vivimos, Segarra se muestra seguro al afirmar la importancia de la misma para entender a esa sociedad en la que se produce.

También para el lingüista Alba (1976, p.64) el hombre como consumidor, o como él prefiere definirlo más concretamente, como "ser con necesidades", depende muy estrechamente de la publicidad. Refiriéndose a la filosofía de la abundancia que impera en nuestra civilización Alba (1976, p.65) asevera que esta profusión de bienes y servicios ha abierto un nuevo camino a las relaciones humanas, ya que la sociedad actual se caracteriza tanto por una producción de objetos como por una producción acelerada y perecedera de nuevas ideas y relaciones. De esta forma "todo este panorama vertiginoso e inquietante se ha convertido en una ideología que afecta a todo el ambiente humano: cultura, arte, ocio, objetos, moda, etc".

El filósofo Lipovetsky (1990, p.213) asegura que la publicidad ha entrado a formar parte del proceso de estética y decoración generalizado de la vida cotidiana, paralelamente al diseño industrial, a la renovación de los barrios antiguos, a la indumentaria a la última, a la decoración de los escaparates y al paisajismo. "Por la misma razón que la moda, la publicidad se dirige principalmente al ojo; es promesa de belleza, seducción de apariencia, ambiente idealizado, más que información" (Lipovetsky, 1990, p.213). Pero un paso más allá de estas manifestaciones de homogeneización social, y paralelamente a la promoción de los objetos y de la información, la publicidad se esfuerza por acentuar el principio de individualidad. "Provoca masificación en lo inmediato y en lo visible, pero a largo plazo y de manera invisible, desestandarización y autonomía subjetiva. Es una pieza clave en el avance social democrático" (Lipovetsky, 1990, p.213).

Para el historiador norteamericano Daniel Boorstin (citado por Armand y Michèle Mattelart, 1987, p.173) habría que distinguir muy claramente entre la experiencia de la sociedad norteamericana y la de las sociedades europeas. Boorstin advierte que en el viejo mundo la alta cultura es la que ha contribuido a organizar el consenso de los diferentes grupos sociales, mientras que Estados Unidos es el primer pueblo que ha dispuesto de una cultura popular organizada centralmente y producida masivamente. Boorstin llega incluso a afirmar que "la crítica de los medios es una forma disfrazada de criticar a la sociedad americana" porque para él la publicidad es uno de los mayores democratizadores que la sociedad haya conocido nunca, porque suministra a la masa la información sobre los nuevos productos y los nuevos servicios, reservada antes a una élite. Y concluye que lo que los críticos objetan no es la publicidad en sí misma, sino "el hecho de permitir que cada uno tenga acceso a la misma información y de derribar un obstáculo, más entre la masa de desarrapados y el puñado de quienes se autoproclaman como los elegidos".

El informe Interpublic Group Annual Report 1986, recogido por el sociólogo Mattelart (2000, p.119), también incide en este punto de la democratización de la sociedad que supone la publicidad en nuestro actual sistema económico. En el que se asegura que la libertad de expresión comercial es tan esencial para el sistema de la democracia económica como la libertad de expresión política para el funcionamiento de la democracia política. 
Viéndola desde un punto de vista económico encontramos las argumentaciones de López Lita con las que demuestra cómo la comunicación contribuye en gran medida a la democracia en el sentido de que eleva el nivel de calidad de la información, consiguiendo así "la necesaria madurez social" (2000, p.41). Por otro lado, considera López Lita (2000, p.58) que la comunicación también favorece a la creación de empleo, ya que los medios de comunicación colaboran en crear el clima social adecuado para el nacimiento de nuevas empresas.

Toda la autoridad de que goza la publicidad se sustenta en la confianza del consumidor, en el momento en que ésta desaparece se produce una drástica reducción del presupuesto publicitario, lo que conlleva que no se produzcan sus efectos beneficiosos. Esto lleva a descartar las acusaciones que con frecuencia se escuchan en contra de la publicidad (López Lita, 2000, p.42).

Tan importante considera Ogilvy (1986, p.215) el papel de la publicidad en nuestro sistema social que llega a afirmar que "una buena agencia de publicidad representa a los intereses del consumidor dentro del Consejo de Administración de una industria".

\section{OBJETIVOS}

Se nos plantea como principal objetivo de esta investigación comprobar si realmente la trascendencia que ha tenido la publicidad para la economía de mercado y la sociedad, es tal, que sería pertinente la creación de un museo internacional de publicidad. En cierta forma, se trata de comprobar si esta institución serviría como carta de reconocimiento y legitimación social de la materia.

Otro objetivo planteado es evidenciar si en el momento actual resulta pertinente plantearse la realización de un proyecto tan ambicioso como sería la creación de un museo internacional de publicidad. Dejando de lado la difícil situación económica internacional de profunda recesión, este objetivo será planteado desde dos aspectos diferentes:

1. Demostrar que los cambios que se están produciendo en la actualidad en la forma de concebir la comunicación publicitaria pueden hacer que éste sea el momento adecuado para tratar de explicar por una nueva vía en qué consiste la disciplina publicitaria.

2. Comprobar si existe algún proyecto similar.

\section{METODOLOGÍA}

Tras la primera aproximación teórica se ha desarrollado el trabajo de campo con una primera fase consistente en la búsqueda y análisis de los museos de publicidad con sede física que existen en la actualidad, para lo cual se ha utilizado como herramienta principal el "medio por excelencia para la actividad científica internacional" (Colás, 2009:87): Internet. Un medio que permite al investigador "dotarse de sistemas más analíticos y exhaustivos de búsqueda, sistematización y recuperación de la información audiovisual" (Vilches, 2011, p.24). 
Por tanto, al tratarse de una búsqueda mundial se ha considerado este medio como el más adecuado para realizar una primera investigación de campo, que posteriormente se reforzó con la visita física a tres de los museos que surgieron como resultado de la búsqueda.

Aunque el investigador de hoy tiene a su disposición una gran herramienta de documentación universal en Internet y a un diligente buscador en Google, recuerda Vilches (2011, p.29) que la tarea más difícil, continua siendo la del investigador, ya que ha de poseer la competencia para buscar, seleccionar y evaluar los documentos que encuentra de manera tan fácil. "Una de las competencias necesarias son las características que debe poseer un documento para ser tenido en cuenta en la práctica de la investigación".

La observación es el método básico e imprescindible para realizar un registro de los datos, se trata del registro de patrones de conducta del fenómeno de interés. Se trata de una observación estructurada ya que las investigadoras especificarán el objetivo a observar y la metodología (Soler en Vilches, 2011, p.199).

La observación directa de campo es útil tanto para la recopilación de datos como para la formulación de hipótesis y teorías y, como todas las técnicas cualitativas, se ocupa más de la descripción y explicación que de la medición y cuantificación (Wimmer y Dominick, 1996, p.146).

Para realizar este trabajo se ha empleado un método analítico descriptivo junto con un análisis cualitativo de los datos obtenidos. Para el análisis descriptivo se ha procedido a un rastreo de la web a través tanto de páginas en castellano como en inglés.

Dentro del totum revolutum que supone Internet a la hora de realizar una investigación científica, lo primero y esencial consiste en saber qué se busca y hacia dónde se orienta la búsqueda; ello implica la necesidad de acotar bien el objeto de la búsqueda con el fin de no perderse en detalles y separar lo importante de lo contingente.

Así, a la hora de buscar los museos de publicidad físicos, es decir que disponen de un edificio donde realizar esta función, existentes en el mundo, la acotación impuesta fue que en su propia denominación apareciese la palabra publicidad (sin importar el idioma) es decir, que la investigación se centra en aquéllos que tienen entre sus principales funciones y contenidos abordar materias publicitarias.

\section{RESULTADOS}

El corpus de la investigación lo han compuesto los seis museos que cumplen los requisitos explicados en la metodología.

Se encontró un séptimo museo de publicidad, The Eisner American Museum of Advertising \& Design (Milwaukee, EE.UU), cuya página web (http://www.eisnermuseum.org) es todavía visible, pero se encuentra cerrado al público desde 2010. Este museo estaba concebido como un centro interactivo y educacional dedicado a la publicidad y al diseño y a su impacto en la cultura.

\subsection{Musée de la Publicité de París}


Les Arts Décoratifs 107, rue de Rivoli, 75001 París (Francia)

La información sobre este museo se ha conseguido a través de su página web (http://www.lesartsdecoratifs.fr ) consultada por última vez en octubre de 2014 y tras una visita al mismo realizada en junio de 2010.

El Musée de la Publicité de París es una institución museística que se centra especialmente en la exhibición de carteles publicitarios, en el contexto de lo que denominan "las artes decorativas". Abrió sus puertas en 1978, pero fue a partir de 1981 cuando pasó a formar parte del Museo de las Artes Decorativas, situado en el ala oeste del Museo del Louvre. Desde 1999, fecha en la que abrió el museo tras una profunda renovación fue rehabilitado para acoger en el interior de un mismo edificio los tres museos que componen el Musée des Arts Décoratifs: Artes Decorativas, Moda y textil y Publicidad, los cuales se pueden visitar con un solo billete de entrada. El museo es de propiedad privada, se encuentra bajo la ley de las asociaciones sin ánimo de lucro y está reconocido como bien de interés público. Sus fondos pertenecen a la colección nacional, que es mantenida, al igual que las nóminas de los trabajadores, con fondos públicos. Sin embargo, tienen que buscar apoyos para las exposiciones, que en su mayoría vienen de los Amigos del Museo.

Esta institución dispone de carteles publicitarios antiguos y contemporáneos, así como películas, objetos y soportes publicitarios. Su colección abarca la historia de la publicidad desde finales del siglo XVIII hasta nuestros días, pero como anuncian en su web, las obras de sus colecciones son demasiado frágiles para ser puestas en exhibición permanente, por lo que se presentan como exposiciones temporales. Al no disponer de una colección permanente, su actividad museística está concebida como un espacio para la presentación de exposiciones temporales, que se van renovando constantemente. Acoge a razón de tres o cuatro exposiciones temporales por año. La idea es mostrar las tendencias artísticas y sociológicas de la sociedad en las décadas en un mundo donde el consumismo ha sido un fenómeno creciente.

Con más de 80.000 carteles antiguos y contemporáneos, el Museo de la Publicidad de París dispone en sus fondos de una historia del cartel publicitario francés desde finales del siglo XVIII hasta nuestros días. Conserva además 50.000 carteles contemporáneos (de 1950 a la actualidad); más de 20.000 películas francesas o extranjeras (a partir de los años 30 hasta nuestros días); más de 30.000 anuncios de prensa; anuncios de radio y objetos promocionales.

Por otro lado, el Museo de la Publicidad de París ofrece en su página web cuantiosa información organizada alrededor de diferentes temas: historia de la publicidad, marcas y personajes, oficios y grandes nombres y actividades.

Además, el Museo de la Publicidad de París ofrece una serie de talleres y conferencias en la sede del museo para grupos escolares, lo que indica la importante vocación del museo como espacio educativo y para la formación de ciudadanos críticos con el discurso publicitario.

La página web del Museo de la Publicidad de París tiene una sección dedicada a los recursos para el estudio de la publicidad, si bien no se pueden consultar on line más que unas pocas informaciones, relativas a dónde estudiar publicidad, un diccionario de la profesión, o la relación de contenidos relacionados con el mundo de la 
publicidad emitidos en el programa de televisión "Culture Pub" por la cadena de televisión francesa M6.

El museo dispone de: una sala de exposiciones de $700 \mathrm{~m}^{2}$ donde se realizan las exposiciones temporales, una sala de consulta de sus fondos, abierta al público, donde se pueden consultar las colecciones del museo y revistas especializadas (estos datos no son accesibles desde la página web). La base de datos que ofrece el museo se limita exclusivamente a la publicidad francesa. Y una sala de documentación, solo accesible para profesionales, previa autorización con tres tipos de materiales:

1. documentos acerca de temas concretos como "la mujer en la publicidad", "los niños en la publicidad", "el arte en la publicidad", "arquitectura, cine y publicidad"...

2. gráficas organizadas por productos, autores, ilustradores, fotógrafos...

3. más de 500 libros sobre publicidad y revistas de publicidad.

\subsection{The Museum of Brands, Packaging and Advertising de Londres}

2 Colville Mews, Lonsdale Road, Notting Hill, London, W11 2AR (Reino Unido)

La información sobre este museo se ha conseguido a través de su página web (http:/ / www.museumofbrands.com) consultada por última vez en octubre de 2014 y tras una visita al mismo realizada en abril de 2011.

The Museum of Brands, Packaging and Advertising de Londres está dedicado a la exhibición de publicidad, marcas y packaging. Alberga 12.000 piezas cedidas por su fundador, Robert Opie, y propone un recorrido histórico a través de la historia de la publicidad, especializado en envases y otros productos que han servido para la comunicación publicitaria. Se trata de una iniciativa bastante singular en el mundo, que cuenta con el patrocinio de importantes anunciantes como Kellog's, Cadbury, Vodafone, Twinings o Nestlé.

Entre 1984 y 2001, la colección estuvo alojada en el Museo de la Publicidad y Envases de Gloucester. En diciembre de 2005 se trasladó a Londres con la colaboración de la consultora de comunicación Pi Global que, además de ayudarle a recaudar fondos junto con otros patrocinadores claves, cooperó para que el museo alcanzase la condición de institución benéfica. Su objetivo de caridad es promover la educación del público en el diseño y, en particular sobre la de historia del packaging y la publicidad.

Está situado en una casa rehabilitada a tal fin. Toda la parte pública se encuentra situada en la planta baja de un edificio de una planta. Además de la sala de exposición, dispuesta a modo de "pasillo" por el que se realiza el recorrido cronológico, dispone de una sala multiuso en la que se celebran conferencias y se alquila para eventos privados y de una recepción que también hace las veces de tienda de recuerdos.

En este pequeño museo se encuentran marcas y envases, carteles y anuncios, así como las modas, juguetes y juegos del último siglo en el Reino Unido, a modo de caleidoscopio de imágenes y marcas icónicas. A través de un "túnel del tiempo" se realiza un viaje nostálgico desde la época victoriana hasta la actualidad, es decir, que a través de los productos domésticos y los favoritos de los consumidores se traza la historia de la cultura de consumo. En él se puede descubrir cómo las marcas han 
evolucionado a través del uso creativo de los envases y la publicidad y cómo el público ha evolucionado con ellos.

El Museo de Marcas, Packaging y Publicidad es parte de una iniciativa privada, presenta la colección del historiador de los consumidores, Robert Opie, quién sintió la necesidad de registrar la historia de los productos cotidianos. Empezó a recopilar materiales a los dieciséis años y creó una colección que ahora se extiende a todos los aspectos de la vida cotidiana: juguetes, revistas, tecnología, viajes, recuerdos, moda y diseño. Él mismo comenta en la web: "cuando las miles de piezas de nuestra historia social, son ensambladas dentro de un rompecabezas gigante, el panorama resulta más claro".

En el museo se han realizado exposiciones relacionadas tanto con la historia de las marcas como con su comunicación, y sobre los embalajes. También se realizan talleres como los "Designplus. Talleres retorno al Museo de Marcas", que son talleres que se realizan durante tres días para desarrollar habilidades estratégicas dirigidos a los profesionales que intervienen en la comercialización, la marca y el diseño.

Se asegura en la web de uno de los patrocinadores principales (http://www.piglobal.com) que este museo atrae a más de 25.000 visitantes de todo el mundo entre profesionales, estudiantes y público en general.

Ofrece la posibilidad de realizar visitas guiadas para escolares con diferentes actividades didácticas y hojas de trabajo para diferentes edades y niveles educativos. Uno de los temas que se tratan son los derechos de propiedad intelectual.

\subsection{The Advertising Museum of Tokyo (ADMT)}

Caretta Shiodome, 1-8-2, Higashi-Shinbashi, Minato-ku. Tokio (Japón)

La información sobre este museo se ha conseguido a través de su página web (http://www.admt.jp/en/) consultada por última vez en octubre en de 2014 y tras una visita al mismo realizada en diciembre del 2007.

Situado en Tokio pertenece a la Fundación Yoshida Hideo. Se trata de una institución sin ánimo de lucro, fundada en 2002 con el apoyo del Ministerio de Educación, Cultura, Deportes, Ciencia y Tecnología del estado japonés.

El objetivo principal del ADMT se enmarca dentro del de la fundación "promover el marketing, especialmente la publicidad, estimulando el estudio de estas actividades y el enriquecimiento de los aspectos teóricos y técnicos del marketing y de la publicidad, para contribuir a un avance de la economía, la industria y la cultura de Japón".

La adquisición de material antiguo se realiza mediante compra en anticuarios, mientras que la publicidad actual la recogen a través de las piezas que se presentan a los diferentes concursos sobre los cuales se realizan las exposiciones temporales.

Su colección consta de unas 170.000 piezas, de las cuales más de 100.000 están digitalizadas. Entre este material figuran 20 planchas xilográficas impresas en el periodo Edo (1603-1867). Son muy cuidadosos con los derechos de autor de los anuncios, por lo que el material no se puede grabar, imprimir ni fotografiar y una gran parte de su archivo sólo puede verse en los equipos informáticos del museo.

La exposición permanente que posee esta institución ofrece una panorámica de la historia de la publicidad en Japón y está accesible para investigadores, estudiosos y 
profesionales de la publicidad. Se centra principalmente en el estudio de la evolución de la publicidad gráfica, centrada especialmente en el conocimiento del cartel publicitario. Otras formas de expresión publicitarias como el spot para televisión, las cuñas de radio, Internet, etc., tienen su espacio en los fondos documentales del museo, así como en la colección que se exhibe de forma permanente.

El Museo de la Publicidad de Tokio se centra, de forma exclusiva, en el estudio de la evolución de la publicidad en ese país, para lo cual propone un recorrido a través de una serie de salas que están organizadas por periodos históricos, desde el periodo Edo (siglos XVII y XVIII), pasando por el modernismo, el periodo de entreguerras, etc. En un apartado se hace una comparación con la sociedad, vida y cultura de cada una de las últimas décadas del siglo XX, donde se expone un collage de productos populares de la época y en los paneles de enfrente se muestra la publicidad de ese periodo, tanto a través de anuncios gráficos como spots televisivos, ello permite a los visitantes poder comprender la relación entre la sociedad y la publicidad.

Además de la exposición permanente, el museo ofrece exposiciones temporales y dispone de una completa biblioteca en la que el visitante o investigador puede consultar publicaciones especializadas. Esta biblioteca cuenta con unos 12.000 volúmenes, de los cuales unos 2.700 son extranjeros, además de 160 revistas especializadas en los campos de la publicidad y del marketing. Además, en ella se pueden consultar materiales digitalizados y originales, que están disponibles en una serie de terminales del museo. Asimismo, la biblioteca, o fondo documental del museo, tiene entre sus fondos cuantioso material procedente de los festivales internacionales que tienen lugar en Asia sobre publicidad, lo que es de especial interés para los investigadores.

Esta institución pública periódicamente la revista AD Studies, de la que se editan tres números al año.

Además el ADMT coordina el "Japan Magazine Advertising Awards", un premio anual que se concede a la mejor publicidad publicada en revistas de Japón. Se trata de un certamen que se inició en 1958.

Financieramente esta fundación es totalmente independiente. Sus ingresos provienen de la inversión, el uso de activos y de los intereses y dividendos de fondos básicos. El acceso es gratuito.

El museo tiene una superficie de $1.200 \mathrm{~m}^{2}$ y se encuentra ubicado en una parte de la $1^{\mathrm{a}}$ y $2^{\mathrm{a}}$ planta del rascacielos de Dentsu, en pleno distrito de oficinas de Tokio. Por tanto, el museo no dispone de un edificio autónomo, sino que está integrado, junto a gran número de tiendas y restaurantes, dentro del complejo del edificio Dentsu y su entrada principal está en el segundo piso.

En la planta superior se encuentra ubicada la entrada al museo, la tienda, una sala con ordenadores para realizar búsquedas en las colecciones del museo y la única biblioteca sobre publicidad que hay en Japón.

La $2^{\mathrm{a}}$ y $1^{\mathrm{a}}$ planta del museo están conectadas por unas escaleras interiores que denominan "Exhibition Hall". En este espacio es donde se ubican las exposiciones temporales. 
En la planta inferior se encuentran las exposiciones permanentes dedicadas a los principios de la publicidad en Japón, de finales de la era Edo (1603 - 1868) y principios de la era Meiji (1868 - 1912). A continuación se accede a la sección de anuncios del S. XX: Exposición de anuncios de la era Taisho (1912 - 1926), Showa (1926 - 1989) y Heisei (1989 - ). Finaliza el recorrido en el "Hall Audiovisual", un espacio multifuncional en el que se proyecta la película "Publicidad - Espejo de la sociedad".

El objetivo de la fundación es el de dar soporte a los estudiantes en el campo del marketing y publicidad y contribuir a la mejora de la ciencia, economía y cultura de Japón a través de la difusión y desarrollo de teorías y tecnologías de publicidad y marketing. Para lo cual subvenciona estudios de marketing y publicidad, subcontrata estudios e investigaciones en Japón y el extranjero, publica el boletín trimestral Ad Studies y gestiona la dirección del Museo de Publicidad de Tokio.

Esta institución dispone de página web (http://www.admt.jp/en/index.html) pero no puede ser considerada como un museo virtual dado que en ella no se pueden realizar búsquedas de anuncios, es simplemente un soporte publicitario para el propio museo, con información relativa a la entidad, sus servicios, las exposiciones y actividades que realizan.

\subsection{The Korea Advertising Museum (Seúl, Corea del Sur)}

Sincheondonggil dong, Songpa-gu, Seúl 138-927 10 (Corea del Sur)

La información sobre este museo se ha conseguido a través de su página web (http:/ / admuseum.kobaco.co.kr/) consultada por última vez en noviembre de 2014, esta web en noviembre de 2011 no se encuentra disponible y en esa fecha la web del museo pasa a estar ubicada en la siguiente URL: http:/ / admuseum.kobaco.co.kr/

Esta entidad está promovida por la empresa Kobaco (Korea Boradcast Advertising Corporation). Ubicado en el tercer piso del centro cultural Korea Advertising Culture Center en Shincheon-dong, Songpa-gu, el Korea Advertising Museum fue inaugurado en Noviembre de 2008 y en él se recoge la crónica de 120 años en la historia de la publicidad coreana.

Con una dimensión de $912,4 \mathrm{~m}^{2}$, dispone de dos salas de conferencias, biblioteca y ocho diferentes salas de exposiciones separadas por temas y materias: origen de la publicidad; la historia social y cultural de Corea a través de los anuncios; anuncios que mueven el mundo; cómo se produce la publicidad; la experiencia de hacer anuncios; anuncios institucionales; video hall para la educación en anuncios y archivo digital.

El museo expone un documental sobre anuncios a página completa en el periódico Hwangseong Shinmun en 1886, así como otras gráficas y spots de hace más de cien años. El archivo digital dispone de más 45.000 imágenes entre videos y anuncios impresos, que van desde el año 1186 hasta nuestros días, de los cuales: 17.852 son spots nacionales y 349 internacionales; 3176 cuñas de radio; 20.226 anuncios gráficos y 4.207 piezas de otros tipos de publicidad. Algunos de ellos se pueden descargar desde su página web. 
Ofrece al visitante la oportunidad de experimentar haciendo un anuncio, tomando fotos y editándolas. También se puede realizar un paseo virtual en motocicleta para ver la publicidad exterior. Disponen de un programa cultural dirigido a públicos diversos. Han desarrollado un programa educativo para niños y jóvenes en colaboración con el Instituto de la Publicidad.

La recogida de información sobre esta institución ha sido complicada debido a que su página web es únicamente en coreano y el traductor no puede acceder a todo el contenido del site.

\subsection{Advertising Icon Museum (Kansas, EE.UU.)}

La información sobre este museo se ha conseguido a través de su página web (http://advertisingiconmuseum.org/ ) y a través del correo electrónico mantenido con Howard Boasberg, Director Ejecutivo del museo.

Se trata de un museo que tenía previsto abrir sus puertas en 2011, en Kansas City, EE.UU, pero según indican en su página web, en la actualidad está abierto pero con la solicitud previa de cita para poder visitarlo.

Esta institución alberga algunos productos comerciales que han alcanzado un alto reconocimiento de marca. Se trata de marcas que se han hecho un hueco en el léxico de la vida cotidiana y han marcado la sociedad y la cultura americanas.

Los visitantes pueden explorar a través de artefactos auténticos y vívidos relatos cómo se utilizan los iconos para vender productos y al hacerlo, reflejan las aspiraciones, los deseos y los valores culturales de la época en que fueron creados. Se trata de un estudio de la historia y un relato de lo que sucede en el momento actual. La intención es realizar un museo vivo que evolucione con los tiempos.

La misión del museo es educar a la opinión pública y mejorar la apreciación y comprensión de la publicidad y los productos de marca mediante la utilización de iconos de la publicidad y personajes de ficción, y para explorar cómo estos iconos reflejan los valores sociales y culturales. La educación es un elemento clave del museo, se están desarrollando programas educativos para mejorar la experiencia del público.

El museo alberga una colección de 3.000 piezas compuesta de objetos tridimensionales y originales de materiales impresos y cuenta con anuncios de radio y televisión.

\subsection{Castello di Rivoli Museo d'Arte Contemporanea}

Piazza Mafalda di Savoia - 10098 Rivoli - Torino.

http://www.castellodirivoli.org/?lang=en

El castillo de Rivoli, rehabilitado en 1984 como sede del Museo de Arte Contemporáneo, cuenta entre sus colecciones con una titulada "Museo de la publicidad".

Este museo fue fundado con la adquisición de la colección de RAI Spira, empresa comercializadora de todos los medios de la marca Rai. Este departamento tiene como objetivo presentar la publicidad como referente artístico y lenguaje expresivo, como 
influencia en el contexto social y la cultura asociada al mundo de los negocios y las estrategias de comunicación.

La colección incluye 2000 carteles y bocetos italianos originales datados de 1930 a 1980. La mayoría de ellos son donaciones de las familias de Dino Villani, Severo Pozzati y de cartelista Nico Endel e incluye el trabajo de artistas como Dudovich, Cassandre, Armando Testa, Gino Boccasile, junto con carteles de la Enit (Ente Nazionale Italiano per il Turismo, el Patronato Italiano) y de otros organismos públicos.

El material audiovisual de la colección incluye spots para cine y televisión, y toda la colección de películas publicitarias que han ganado premios en los festivales internacionales de Cannes y Venecia desde 1954. El total de las 30.000 campañas que recoge esta colección representan el período comprendido entre la década de 1950 y la actualidad. De estas, unas 8.000 han sido catalogadas y digitalizadas.

La consulta de esta documentación se realiza a través de una estación de trabajo con la asistencia del personal del museo.

La mediateca está abierta al público con cita previa.

\section{DISCUSIÓN}

Actualmente existen multitud de museos que disponen entre sus fondos de materiales publicitarios. Asimismo, en Internet también hay infinidad de páginas web que muestran piezas publicitarias, pero físicamente, a finales de 2014, solo hay en el mundo seis museos que están dedicados en profundidad al tema y entorno de la publicidad y así lo recogen en su nombre, aunque ninguno de éstos lo hace de forma general, sino sesgada, es decir, que o bien se centran en un soporte concreto, o bien en un ámbito de actuación muy específico pero en ningún caso tienen vocación internacional ni abordan el fenómeno en toda su extensión.

Por ejemplo, la concepción del Musée de la Publicité de París contiene algunos elementos muy interesantes, como el planteamiento didáctico o la iniciativa de la web como espacio repositorio de información para el público en general. Se trata de una propuesta mejorable, desde el punto de vista de la internacionalización y del desarrollo de la base de datos sobre producción publicitaria, que podría ser más rica y completa ya que se limita exclusivamente al panorama de la publicidad francesa.

El principal atractivo de este museo es su ubicación en una zona eminentemente museística de la ciudad, en el mismo edificio del famoso museo del Louvre, pero quizá por ello mismo, la grandiosidad del Louvre deja un poco en paños menores al Museé des Arts Decoratifs en el que está enmarcado el Museé de la Publicité. Incluso dentro del propio Museé des Arts Decoratifs, el apartado dedicado a la publicidad es considerablemente menor que el resto.

Su web no puede considerarse un museo, aunque tenga una sección dedicada a los recursos para el estudio de la publicidad, ya que no se pueden consultar on line más que unas pocas informaciones, relativas a dónde estudiar publicidad, un diccionario de la publicidad, o la relación de contenidos relacionados con el mundo de la publicidad emitidos en el programa de televisión "Culture Pub" por la cadena de televisión francesa M6. 
Por su parte The Museum of Brands, Packaging and Advertising de Londres está planteado como un lugar de visita para conocer la evolución de los envases publicitarios y de otros objetos, desde tiempos pasados hasta nuestros días. Básicamente se trata de un espacio dedicado a la nostalgia. Este museo, sin embargo, no se propone como un espacio para la investigación, ni como un centro de documentación on line para los visitantes de la página web, que posee muy poca información.

The Eisner American Museum of Advertising \& Design (Milwaukee, EE.UU), que permaneció abierto al público durante 10 años, pero que permanece cerrado en la actualidad, parecía una iniciativa cultural muy interesante, especialmente, en lo referente a la concepción de las exhibiciones temporales, que se planteaban con frecuencia de forma temática y no histórica, lo que podía resultar estimulante para relacionar conceptos o para despertar una reflexión entre los visitantes. No obstante, entre los principales problemas o defectos que se podían destacar se encontraba la inexistencia de un fondo permanente, la ausencia de una biblioteca o fondo documental, la ausencia de un desarrollo de una línea virtual para la consulta de los fondos on line, la falta de un planteamiento internacional en el estudio de la publicidad y el diseño, así como el hecho de no aglutinar a su alrededor el desarrollo de investigaciones concretas sobre el fenómeno de la comunicación publicitaria.

The Advertising Museum of Tokyo (ADMT) (Japón), perteneciente a la Fundación Yoshida Hideo y situado en Tokio (Japón), es tal vez el referente más interesante de los pocos que existen en la actualidad en el mundo. En su declaración de intenciones subraya algunos aspectos muy importantes como la necesidad de impulsar el estudio de la publicidad y el hecho de que la labor divulgativa del museo contribuye, en cierta medida, al avance de la economía y la cultura del país.

Un aspecto llamativo del Museo de Tokio es que se centra, de forma exclusiva, en el estudio de la evolución de la publicidad en ese país sin establecer ninguna relación entre la publicidad de Japón y el resto del mundo, lo que constituye un serio problema de concepción. Una de las partes más interesantes de la exposición radica en el estudio de la publicidad gráfica aparecida en carteles, periódicos, revistas y otros soportes, que por décadas va ofreciendo una visión sobre la relación entre la publicidad y la sociedad de cada momento histórico. A pesar de ello, el Museo de la Publicidad de Tokio es, en estos momentos, el museo más completo que existe en su género en todo el mundo, si bien presenta una serie de déficits como la falta de visión internacional o la ausencia de soportes tan importantes como Internet, marketing directo o publicidad exterior entre otros.

The Korea Advertising Museum (Seúl, Corea del Sur) es el más recientemente inaugurado de los seis museos de publicidad que en la actualidad se encuentran en el mundo y quizá por ello incorpora algún elemento interactivo más que sus precedentes, como puede ser la posibilidad de realizar una visita virtual en moto para visualizar los soportes de publicidad exterior, uno de los grandes medios olvidados por el resto de museos.

$\mathrm{Al}$ igual que sus precedentes, su exposición permanente se centra en la historia de la publicidad del país que le acoge, pero dispone de un archivo digital con referencias internacionales. Además de biblioteca y salas para conferencias dispone de un 
programa educativo desarrollado en colaboración con el Instituto de la Publicidad y de un programa cultural dirigido a públicos diversos.

Por otro lado, el Advertising Icon Museum (Kansas, EE.UU.) es incógnita porque en su página web estuvieron anunciando su inauguración durante varios años y cuando por fin esta se produjo solo es posible visitarlo con cita previa. Su intención es centrar la exposición en una muestra de iconos y personajes de ficción publicitarios para explorar cómo reflejan los valores sociales y culturales. Otro propósito que tienen es desarrollar programas educativos que mejoren la experiencia del público. Pero a finales de 2014 parece que la actividad que desarrollan, según su propia web y perfil en redes sociales, es más bien poca.

El Museo de la Publicidad del Castelló di Rivoli, pese a su nombre, se queda en una colección más dentro de un museo de arte contemporáneo y es por ello que únicamente se centra en la publicidad como referente artístico y lenguaje expresivo, pero sin profundizar en los múltiples aspectos que como se ha visto en este estudio están implicados en la disciplina publicitaria.

En definitiva, y pese a la gran vinculación social y económica que la disciplina publicitaria mantiene con la actual economía de mercado, todavía no existe ninguna institución museística que esté tratando el tema de una forma científica, multidisciplinar y a nivel global.

Si bien es cierto que tratar una materia tan amplia a nivel mundial puede resultar una tarea ardua, y quizá resulte más interesante centrar la materia de estudio en un ámbito acotado como puede ser el nacional, no es menos cierto que en un mercado globalizado el estudio de la disciplina publicitaria no puede dejar de establecer relaciones con el resto de territorios, ni dejar de conocerlas. En definitiva, se trataría de centrar la colección en la publicidad nacional, pero abordando también la investigación y colaboración internacional, quizá a través de exposiciones temporales, que permitieran conocer cómo se abordan los problemas de comunicación desde diferentes puntos del planeta. Es decir, no quedarse en la mera exposición de piezas internacionales, sino que esa muestra sea resultado de una investigación. Las muestras deberían tener un contenido expositivo más allá del puramente creativo, fruto del palmarés de algún certamen internacional, como en la actualidad acontece en las exposiciones temporales del Museo de la Publicidad de Tokio. La investigación como base de cualquier exposición, esta debería ser la premisa principal.

\section{REFERENCIAS}

\section{Publicaciones periódicas:}

Alonso, L. (2006). Museología y museografía. Barcelona: del Serbal. (1 a edic.1999).

Baudrillard, J. (2009). La sociedad de consumo. Sus mitos, sus estructuras. Madrid: Siglo XXI de España Editores.

Colás, M. (2009). La investigación educativa en la (nueva) cultura científica de la sociedad del conocimiento, en XXI: Revista de Educación, 4(0). Recuperado de http://uhu.es/publicaciones/ojs/index.php/xxi/article/view/623/958.

Consultado el 23/09/2014 
Riaño, E. (2004). La renovación museográfica del Museo del Oro en Boletín Museo del Oro, (Bogotá) 52. Recuperado de http://www.banrep.gov.co/museo/esp/boletin. Consultado el 05/05/2014.

\section{Artículos en papel y electrónicos:}

Advertising Icon Museum: http:/ / advertisingiconmuseum.org

Castello di Rivoli Museo d'Arte Contemporanea:

http://www.castellodirivoli.org/?lang=en

Les Arts Decoratifs: http:/ / www.lesartsdecoratifs.fr

The Eisner American Museum of Advertising \& Design:

http:/ / www.eisnermuseum.org y http://www.theeisner.com/

The Korea Advertising Museum: http:/ / www.kacm-museumq.or.kr/ y

http://admuseum.kobaco.co.kr/

The Museum of Brands, Packaging and Advertising:

http://www.museumofbrands.com

The Advertising Museum of Tokio: http://www.admt.jp/en/

http:/ / www.piglobal.com

\section{Capítulo de un libro o entrada de un libro de consulta:}

Eguizábal, R. (1998). Historia de la publicidad. Madrid: Editorial Eresma \& Celeste.

García Serrano, F. (2000). El museo imaginado. Recuperado de

www.museoimaginado.com/TEXTOS/Museo.pdf. Consultado el 26/06/2014.

León, A. (1990). El Museo. Teoría, praxis y utopía. Madrid: Cátedra.

Lipovetsky, G. (1990). El imperio de lo efímero. Barcelona: Anagrama. (1 ${ }^{\mathrm{a} e d i c . e n}$ francés, 1987. L'Empire de léphémère. La mode et son desin').

López Lita, R. (2000). Comunicación: la clave del bienestar social. Madrid: El Drac.

Mattelart, A \& Mattelart, M (1987). Pensar sobre los medios. Madrid: Fundesco.

(Primera edición en francés, 1986).

Mattelart, A. (2000). La publicidad. Barcelona: Ediciones Paidós Ibérica. (1 ${ }^{\mathrm{a}}$ edic.en inglés, 1994. La publicitè).

Moreno, I. (2002). Musas y nuevas tecnologías. Barcelona: Paidós.

\section{Libros completos:}

Alba De Diego, V. (1976). La publicidad (sociedad, mito y lenguaje). Barcelona: Planeta.

Caro, A. (1994). La publicidad que vivimos. Madrid: Editorial Eresma \& Celeste Ediciones.

Ogilvy, D. (1986). Confesiones de un publicitario. Barcelona: Ediciones Orbis. $\left(1^{\text {a }}\right.$ edic. en inglés, 1963. Confessions of an advertising man).

Segarra, T. (2009). Desde el otro lado del escaparate. Madrid: Espasa Calpe.

Vidarte, J. I. (2004). Infraestructuras culturales. Revista de Estudios Vascos 49.

Vilches, L. (coord.) (2011). La investigación en comunicación. Métodos y técnicas en la era digital. Barcelona: Editorial Gedisa 
Wimmer, R.D. \& Dominick, J.R. (1996). La investigación científica de los medios de comunicación. Una introducción a sus métodos. Barcelona: Bosch Casa Editorial.

\section{AUTOR/ES:}

\section{Consuelo Balado Albiol:}

Licenciada en Ciencias de la Información por CEU San Pablo, Valencia y doctora en Ciencias de la Comunicación por la Universitat Jaume I de Castellón.

Su trabajo en el mundo de la comunicación se inició en el apartado del diseño gráfico, más de 7 años, y con el anunciante durante cerca de 2 años.

Ha colaborado más de 4 años con la Asociación de Agencias de Publicidad de la Comunidad Valenciana en diferentes proyectos, entre los que se encuentran la organización de: La Cumbre Empresa, Marca y Comunicación (ediciones I, II y III), el International Advertising Summit and Intercontinental Advertising Cup y La Lluna, Nit de la Publicitat Valencian (ediciones I, II, III y IV). También ha colaborado en el proyecto del VIAM (Valencia Internacional Advertising Museum).

En la actualidad compagina su labor docente en la UJI con la coordinación de la Asociación para el Desarrollo de la Comunicación (adComunica).

Síntesis del currículo del autor de 150 palabras

\section{Eva Breva Franch:}

Doctora en Comunicación Empresarial e Institucional por la Universitat Jaume I (UJI) de Castellón y licenciada en Ciencias de la Información por la Universidad Autónoma de Barcelona. Profesora Ayudante Doctora del Departamento de Ciencias de la Comunicación de la UJI. Acreditada a contratada doctora por la ANECA.

Es en la UJI donde viene desempeñando labores docentes e investigadoras desde el año 2001 en los campos de la Planificación de Medios y la Publicidad Exterior. Su docencia se reparte entre el Grado de Publicidad y Relaciones Públicas y el Máster Oficial en Nuevas Tendencias y Procesos de Innovación en Comunicación. Del resultado de sus investigaciones y de su colaboración con la Asociación Española de Empresas de Publicidad Exterior ha publicado el libro: La Publicidad Exterior. Una mirada de $360^{\circ}$. De la teoría a la acción. Tiene publicados diversos artículos en revistas científicas de prestigio. Pertenece al grupo de investigación Neuroengagement and Communication. 